\title{
Debates para inventar una excepcionalidad: el concepto de populismo en Colombia y su relación con la violencia $(1970-2010)$
}

Cómo citar este

artículo en APA:

Santos, D. E. (2021).

Debates para inventar

una excepcionalidad: el

concepto de populismo

en Colombia y su

relación con la violencia

(1970-2010). Analecta

Política, 11(21), 245-271.

doi: http://dx.doi.

org/10.18566/apolit.

v11n21.a04

\section{Fecha de recepción:}

10.06.2021

Fecha de aceptación:

23.09.2021

Debates to invent an exceptionality: the concept of populism in Colombia and its relation to violence (1970-2010)

\section{DAVID ERNESTO SANTOS GÓMEZ}

Doctor en Ciencias Sociales Facultad Latinoamericana de Ciencias Sociales (Flacso), Argentina Correo electrónico: davidsantosg82@gmail.com 


\section{Resumen}

En este artículo, se analizan los debates sobre la definición del concepto de populismo en Colombia y su relación con el concepto de violencia entre 1970 y 2010. Seguimos la huella de ciertos intelectuales y cómo estos postularon la hipótesis de que la violencia fue consecuencia de los fenómenos populistas que no llegaron al poder, como el gaitanismo y el anapismo, o antecedente de aquellos que sí lo hicieron, en el caso del uribismo. A nuestro juicio, este vínculo entre populismo y violencia construido por los autores hace parte fundamental de la invención de Colombia como un caso excepcional en América Latina. El trabajo se desarrolla gracias a diversas perspectivas de la nueva historia intelectual e intenta conciliar algunas de sus herramientas teóricas y metodológicas para pensar un objeto de estudio propio y estudiarlo desde sus propias dimensiones.

Palabras clave: populismo, violencia, historia intelectual, Colombia, debates.

\section{Abstract}

This article analyzes the debates on the definition of the concept of populism in Colombia and its relation to the concept of violence between 1970 and 2010. Following the footsteps of certain intellectuals and their hypotheses on violence, we also believe that this came as a consequence of several populist phenomena that did not come to power, such as gaitanismo and anapismo, or as antecedents of those that did, as in the case of uribismo. In our opinion, this link between populism and violence constructed by the authors is a fundamental part of the invention of Colombia as an exceptional case in Latin America. The work is developed thanks to different perspectives of the new intellectual history and tries to reconcile some of its theoretical and methodological tools to think of its own object of study and approach it from its own dimensions.

Keywords: populism, violence, intellectual history, Colombia, debates. 


\section{Introducción}

Este artículo presenta de forma acotada los resultados de una tesis doctoral que estudió los debates por la definición conceptual del populismo, y su variante el neopopulismo, en Colombia y su relación con el concepto de violencia. ${ }^{1}$ Cómo, entre 1970 y $2010,{ }^{2}$ ciertos intelectuales postularon la hipótesis de que el populismo que no llegó al poder en Colombia fue antecedente fundacional, o consecuencia, de periodos violentos, lo que, además, construyó una representación del país como un caso anómalo en América Latina. Esa representación, en suma, se transformó en parte de la invención ${ }^{3}$ de la excepcionalidad del país respecto de la región. En los últimos treinta ańos del siglo XX, estos debates se circunscribieron a publicaciones de las ciencias sociales, con énfasis en historia, sociología, economía y ciencias políticas. En la primera década del siglo XXI, los debates se ampliaron a esferas periodísticas en las cuales esos mismos intelectuales publicaron reflexiones sobre populismo, lo que, en últimas, masificó y mediatizó la discusión con un enorme impacto en su cambio conceptual.

No pretendemos ni describir ni analizar los hechos que han sido catalogados de populistas o sus protagonistas colombianos (el gaitanismo y Jorge Eliécer Gaitán, el anapismo y Gustavo Rojas Pinilla o el uribismo y Álvaro Uribe Vélez). Mucho menos ofrecemos una definición del concepto de populismo ni tampoco una tipología de sus definiciones, ni hacemos una comparación conceptual, ni una historia de los intelectuales. Lo que es o no es el populismo da paso a un esfuerzo por revelar de qué forma los debates entre los intelectuales para definir un concepto se revelan como síntomas de otras cuestiones y se transforman en radiografía de una época. En ese sentido, nuestro objeto es un metaobjeto (Ma-

1 La tesis defendida y aprobada en el Doctorado de Ciencias sociales de Flacso Argentina lleva por nombre La invención de la excepcionalidad colombiana: Los debates por la definición del concepto de populismo y su relación con la violencia en Colombia (1970 -2010).

2 La periodización abarca cuatro décadas de debates: desde 1970, cuando aparecen los primeros estudios sobre el concepto, tras las elecciones presidenciales de ese año, hasta el 2010, año en el que termina la presidencia de Álvaro Uribe Vélez, considerado por ciertos intelectuales como populista.

3 La idea de invención es recurrente en las ciencias sociales latinoamericanas. Arturo Escobar escribió en 1998 su libro La invención del Tercer Mundo: Construcción y deconstrucción del desarrollo, en el que explica cómo la idea de desarrollo ayudó a la consolidación del capitalismo y a construir la noción de tercer mundo. En una mirada más cercana a la nuestra, se inscribe el trabajo de Federico Neiburg Los intelectuales y la invención del peronismo de 1988 en el que se analiza cómo el peronismo ha sido objeto de polémica recurrente en Argentina y de qué forma es tratado como un eje central de las discusiones intelectuales en ese país. En otras palabras, cómo lo intelectuales "inventan" el peronismo en cuanto fenómeno. 
grini, 2018): trabajamos con los debates que construyeron una definición y cómo los académicos que participaron en ellos leyeron e interpretaron los procesos que consideraron populistas.

\section{Metodología}

La investigación se inscribió en el amplio y variado campo de la nueva historia intelectual. En palabras de Altamirano (2005), esta puede entenderse más como un campo de estudio que como una disciplina y su asunto es el pensamiento en las experiencias históricas. "Ese pensamiento, sin embargo, únicamente nos es accesible en las superficies que llamamos discursos, como hechos de discurso, producidos de acuerdo con cierto lenguaje y fijados en diferentes tipos de soportes materiales" (p. 10).

Nuestro análisis pretende conciliar algunas de las herramientas teóricas y metodológicas de la nueva historia intelectual para pensar un objeto de estudio propio y abordarlo desde sus propias dimensiones. De las muchas vertientes nos resultan provechosas las herramientas de tres perspectivas. Por un lado, la historia de los conceptos con Reinhart Koselleck, y su propuesta de entender el carácter contingente de los discursos y la formación de conceptos políticos polisémicos y plurívocos. Koselleck ilumina la importancia de estar atento a las condiciones de enunciación de los conceptos y cómo la historia social y la conceptual son interdependientes. La historia conceptual de Koselleck nos aporta la definición de conceptos políticos polisé-micos y cómo estos van más allá de lo que entendemos como palabras.

Un concepto tiene que seguir siendo polívoco para poder ser concepto. También él está adherido a una palabra, pero es algo más que una palabra: una palabra se convierte en concepto si la totalidad de un contexto de experiencia y significado sociopolítico, en el que se usa y para el que se usa una palabra, pasa a formar parte globalmente de esa única palabra. (Koselleck, 1993, p. 117)

La segunda perspectiva es la de Quentin Skinner que insiste en concebir el lenguaje como una herramienta con una fuerte dimensión pragmática. De ahí su insistencia en entender los textos no como transmisores de ideas, sino como actos de habla que acometen una acción y de estar atentos a los contextos de enunciación, además de pensar no solo qué dice un autor, sino qué hacía cuando lo dijo. También nos resulta fundamental la categoría de doble cara de los conceptos politi- 
cos que plantea Skinner para encarar el debate sobre la definición del populismo, un término que es acusado de ambiguo y maleable.

Sería útil prestar atención a un corpus de palabras que cumplen una función tanto evaluativa cuanto descriptiva en nuestro idioma. Esto es, ellas se usan para describir acciones individuales y para caracterizar los motivos por los cuales estas acciones se llevan a cabo. Sin embargo, siempre que se usan para describir acciones, al mismo tiempo, tienen el efecto de evaluarlas. [...] Es decir, pueden utilizarse para realizar actos tales como los de recomendar y aprobar -o bien, los de condenar y criticaraquellas acciones que esos términos describen. (Skinner, 2007, p. 254)

Por último, nos acercamos a las herramientas de la historia de los lenguajes políticos de Elías Palti. Los lenguajes políticos, sostiene Palti (2014), son formas de producción de conceptos políticos, siendo estos polisémicos y contingentes, y su estudio debe poner particular atención a la reconstrucción de los contextos de debate, categoría que pasa a ser eje central de nuestro estudio.

Lo que se busca aquí es, más allá de las distintas respuestas que ofrecieron los sujetos involucrados, comprender cuál era el tipo de cuestiones que se habían puesto en cada caso en debate, qué tipo de dilemas se les planteaba a los mismos y, eventualmente, cómo este suelo de problemáticas se fue reconfigurando a lo largo del periodo considerado. (Palti, 2014, p. 14)

Palti (2014) insiste en la incapacidad de los conceptos por alcanzar su "plenitud" semántica y propone modificar el análisis de estos al concluir que no es que los conceptos no se puedan definir porque cambian, sino que, justamente, cambian porque no se pueden definir. Al reconstruir las condiciones de producción, que entendemos como las posibilidades de emergencia y articulación de los lenguajes, resulta necesario explicitar cómo se usan los conceptos siendo estos históricos y contingentes, y cómo dejan huellas rastreables en los textos.

\section{Diseño de la investigación}

Un objeto (metaobjeto) de estudio como el nuestro que pretende analizar los debates entre intelectuales y desentrañar cómo se ha inventado desde ellos la idea de excepcionalidad del caso colombiano fue abordado desde cuatro dimensiones que se inspiran, se nutren y se mezclan con las categorías mencionadas. Estas son: 
- Suelos de articulación, entendidos como los acontecimientos sociales y políticos que permitieron la emergencia y el vínculo de los conceptos en cuestión y sobre los que estos se sostienen. En ese sentido, la actualización de los debates que seguimos está relacionada con fenómenos políticos que ponen en juego y en disputa la definición de los conceptos y genera lo que hemos denominado picos interpretativos en los que es posible ver un aumento de las producciones dedicadas a estos debates luego de acontecimientos concretos. Estos picos se sostienen sobre hechos políticos, pero no son lineales y, por el contrario, terminan por plegarse unos con otros.

- Contextos de debate, que remiten a los supuestos académicos y teóricos sobre los que se forman las conceptualizaciones de populismo. Aquí encontramos también lo que denominamos casos espejo sobre los cuales los intelectuales miran y reflejan la experiencia colombiana para entenderla como diferente.

- Paradojas en la definición conceptual que hacen parte de la naturaleza polisémica y controversial de los conceptos políticos.

- Articulación dependiente de las definiciones conceptuales, o cómo los debates construyen un vínculo entre los conceptos sin el cual se hace imposible explicar la naturaleza política de estos. Ese vínculo, por momentos, es de dependencia; en otros, de subordinación. En el caso del populismo, el neopopulismo y su relación con la violencia en Colombia, la relación va más allá de las contradicciones y las paradojas, y termina por construirse entre ellos un binomio inseparable; en otras palabras, en Colombia, paradójicamente el populismo no puede definirse si no se incluye en él la violencia.

De esta forma, la historicidad de los conceptos no radica para nosotros exclusivamente en que podamos rastrearlos a lo largo de un periodo y en unos autores específicos, sino en resaltar las huellas de sus propuestas analíticas y entender cómo estos intelectuales reformulan su significación, los redefinen y los recomponen, según los acontecimientos que requieren ser explicados. Aunque los debates mantienen un núcleo explicativo, la maleabilidad del concepto en pugna termina por ser el vínculo con la realidad que aspiran a explicar y, en últimas, que no solo definen, sino que crean. 


\section{El inicio del debate por el populismo en Colombia: décadas de 1970 y 1980}

Los debates por la definición del concepto de populismo en Colombia tienen un punto de partida claro: abril de 1970. Las elecciones presidenciales que se realizaron el 19 de ese mes y que estuvieron a punto de llevar al poder a un partido político autodenominado nacional popular y etiquetado por opositores como populista, generó lo que nombramos el primer pico interpretativo del debate, y produjeron todo un revuelo en el mundo académico que entonces intentó esclarecer un concepto aún inexplorado en ese país. Por menos de 64000 votos (el 1,5\% del total de papeletas) el candidato Gustavo Rojas Pinilla y su partido Alianza Nacional Popular (Anapo) perdieron la posibilidad de llevar al poder ejecutivo un movimiento político populista. ${ }^{4}$ ¿Qué era el populismo? ¿Había existido antes en Colombia?

Dos estudios concentran la primera reacción intelectual enfocada en definir el concepto. El primero es Populismo, de 1970, en el que los jefes del bipartidismo colombiano, Álvaro Gómez y Alfonso López Michelsen (a los que se le suman textos de Belisario Betancur y Alfonso Palacio Rudas) intentan describir el fenómeno tan solo unos meses después del resultado de las votaciones presidenciales y ofrece un claro diagnóstico de su tiempo. La reconstrucción de los lenguajes políticos que usan los intelectuales para producir su definición de populismo pone en evidencia las diferentes posturas que los autores asumieron respecto del concepto y permite penetrar, como sostiene Palti (2014), ese "sustrato problemático que les subyace".

Los autores, sin excepción, presentan un concepto acumulativo y peyorativo del populismo como movimiento demagógico e irresponsable que, aun así, logra un vínculo con las clases populares que no se sienten representadas por los partidos tradicionales. Ese vínculo se establece gracias a las promesas de mejoras económicas en momentos en los que el proceso de modernización los ha dejado rezagados enriqueciendo a una élite y aumentando la brecha entre lo que Belisario Betancur (1970) llamó las dos economías: la de los opulentos y la de los de abajo. En su estudio, Álvaro Gómez concibe al populismo como "un estilo de la política" y a los movimientos que recurren a él como espacios "espontáneos" que cooptan vacíos dejados por las formas tradicionales de la política. Movimientos

4 El conteo de los sufragios otorgó el primer lugar al candidato conservador Misael Pastrana del Frente Nacional con 1625025 votos (40,2 \%). El segundo puesto fue para Gustavo Rojas Pinilla de la Anapo, con 1561468 votos (38,7 \%). Datos de la Registraduría Nacional del Estado Civil, citados por Ayala (2006). 
que "tienen la pretensión legítima de ser el pueblo, de representarlo" (Gómez, 1970, p. 17).

El surgimiento de un movimiento populista como la Alianza Nacional Popular (Anapo) que estuvo cerca de llegar a la Presidencia con Gustavo Rojas Pinilla demuestra, para los autores, un agotamiento del pacto del Frente Nacional que, durante doce años, y aun con cuatro más por recorrer, sustrajo el elemento político de los partidos para dejarlos como camarillas burocráticas desconectadas de las necesidades de los ciudadanos. Esa orfandad del pueblo es aprovechada por la Anapo. Pero ¿quién es el pueblo? Para los liberales López Michelsen y Palacio Rudas, es la "gleba" y el proletariado. Para los conservadores Gómez y Betancur, el pueblo al que apela el populismo es la clase media que quiere aumentar su poder adquisitivo. La Anapo reconoce al pueblo y se conecta con él mediante un discurso en el que promete mejoras en las condiciones de vida más acordes con los anuncios de modernización.

La primera conceptualización del populismo en el país interpreta que el poder no recae en las instituciones democráticas, sino en los grupos económicos.

¿Quién ejerce el poder en Colombia? Si queremos ser francos debemos contestar que ese poder lo ejerce el sector económico. En este se encuentra casi toda la capacidad decisoria no solo porque casi siempre señala las metas de la acción administrativa sino porque determina quién puede llevarlas adelante. (Gómez, 1970, p. 21)

En noviembre de 1971, quince meses después de la acelerada publicación de la compilación de los líderes bipartidistas, vio la luz El populismo en Colombia, del historiador Marco Palacios, ${ }^{5}$ considerado el primer trabajo académico sobre populismo en las ciencias sociales colombianas. Aunque resulta evidente que este responde al mismo pico interpretativo que originó el de los políticos del bipartidismo, la propuesta analítica de Palacios difiere radicalmente. Palacios señala que el populismo "puede ser un insulto", pero, también de la mano de Gino Germani y Torcuato Di Tella, lo reconoce como un fenómeno propio de una sociedad en transición que ingresa en la modernidad y que posibilita la integración de intereses de las masas populares a la democracia. El autor insiste en que el primer populismo colombiano es muy anterior al fenómeno de la Anapo y aparece con Jorge Eliécer Gaitán en su primera etapa en la década 1930 y luego con más con-

5 Anteriormente hemos trabajado la evolución del concepto de populismo en la obra de Marco Palacios (Santos, 2020), donde se realiza un estudio detallado de este trabajo de 1971 y los publicados por el mismo autor sobre el fenómeno hasta la segunda década del siglo XXI. 
sistencia en la década de 1940. El pico interpretativo que representan las elecciones presidenciales de 1970 obliga a un pliegue sobre los hechos de la década de 1940, a una reinterpretación de la figura de Gaitán y del gaitanismo bajo la óptica de un movimiento que cumplía con los elementos esenciales del populismo. Para el autor, el populismo de Gaitán es un "populismo democrático" (Palacios, 1971, p. 45), como una idea de aceptación partidista en la última etapa del caudillo.

La revitalización de la democracia desde Gaitán quedaría trunca por el asesinato del líder (Palacios, 1971). Un populismo que no llega al poder es entonces desde acá y por primera vez en las ciencias sociales colombianas un fenómeno incompleto que desencadena en violencia. La articulación dependiente de conceptos nace en este trabajo, aunque sería desarrollada con fuerza en los estudios de la década de 1980 de Kalmanovitz y Pécaut. Desde estos primeros pasos del debate en Colombia, el concepto de populismo está insubordinado al enfrentamiento armado y cualquier esfuerzo por su definición parece obligado a considerar la violencia como uno de sus desencadenantes. Aquí da sus primeros pasos parte de la invención de la excepcionalidad colombiana, con una mirada del país que no pudo ser. Valga anotar la paradoja de que esa consolidación narrativa de un país extraño se afiance desde postulados académicos como estos que, en contravía al quehacer científico, se sustentan en las elucubraciones contrafácticas de los caminos no recorridos. ¿Qué habría sido del país si la muerte (y el magnicidio) no lo signara?

Para Palacios, tras el ejemplo de Gaitán, la figura de Rojas Pinilla como dictador en el poder (1953-1957) no puede ser considerada populista y deja la Presidencia en mayo de 1957 tras un acuerdo con los partidos políticos que daban forma al Frente Nacional. Posteriormente, la debilidad del acuerdo facilitó la reaparición de Rojas Pinilla como líder de la Anapo que buscaría la Presidencia. Palacios define este segundo momento rojista como un "populismo conciliador" que supera al "populismo democrático" de Gaitán y que, además, cuenta con experiencia en el poder.

Ambos populismos eran la respuesta a una crisis del Estado liberal y nacen como emergencia en la política colombiana por las dificultades del bipartidismo. Sostiene Palacios (1971) sobre la Anapo comparada con Gaitán:

Ambos emergen a la vida nacional en dos momentos diferentes de la estructura económica y la percepción subjetiva de ella. Su ideología (implícita y explícita) que pueden mantener lazos comunes, expresiones lingüísticas comunes, formas agitacionales idénticas, también se alejan mutuamente. El antioligarquismo, el "nacionalismo" y la noción maniquea de la esencia de la vida política-social, no 
bastan para señalar la comunidad entre el populismo democrático gaitanista y el populismo conciliador del anapismo. Lo común a ambos es ser populistas, pero ya advertíamos lo equívoco del término cuando no está referido a las condiciones históricas de su aparición. (pp. 91-92)

Palacios (1971) ve el populismo de Rojas Pinilla como un movimiento más definido, preciso y heterogéneo, aunque sobreviven ciertos rasgos de la ambigüedad que considera constitutiva de este tipo de expresiones políticas. Tendría que pasar una década para que aparecieran nuevos estudios que en las ciencias sociales colombianas pensaran de nuevo en detalle el populismo.

\section{La década de 1980 y la resignificación conceptual}

Afirma Skinner (2007) que, para entender lo que hace un autor al usar un concepto, es necesario "captar la naturaleza y la gama de cosas que podría haber hecho de modo reconocible al usar dicho concepto, en el tratamiento de ese tema en particular, y en ese tiempo específico" (p. 183). El contexto de debate intelectual en el cual se escenifica lo que denominamos el segundo pico interpretativo difiere de aquel en el que se inició la búsqueda de la definición del populismo influido por el desarrollismo y el dependentismo, pues las investigaciones de la década de 1980 son herederas de una profesionalización de las facultades de las ciencias sociales colombianas. ${ }^{6}$

En este ambiente, ven la luz dos trabajos clave para nuestros debates: Economía y nación, del economista Salomón Kalmanovitz en 1985, tras un proceso de una década y media de investigación, y en 1987, la versión en español de Orden y violencia, de Daniel Pécaut. Estos son resultado del segundo pico en el que confluían un interés por entender la violencia guerrillera y las posibilidades de paz en un país atravesado por el enfrentamiento político.

6 Según datos del Instituto Colombiano para la Evaluación de la Educación (Icfes), citados por Leal (1988), en 1940, existían en el país diez universidades: cinco en Bogotá, una en Medellín, una en Cartagena, una en Popayán y una en Pasto, de las cuales cinco eran privadas y cinco oficiales. En la década siguiente, se fundaron siete universidades más, y entre 1951 y 1967, 17 universidades privadas y siete oficiales, lo que llevó ese año a 47 el número de instituciones de educación superior (IES). Al cierre de la década de 1980, existían en Colombia más de un centenar de universidades y cerca del $60 \%$ de ellas de carácter privado. 
Kalmanovitz introduce, desde la economía y la nueva historia, una mirada novedosa sobre el proceso de conceptualización del populismo en Colombia. Para él, la imposibilidad del triunfo populista en las urnas se construye desde unas élites colombianas que tuvieron tiempo para reorganizarse tras el coqueteo popular de López Pumarejo. Esa especie de "advertencia", de ventana al futuro de lo que podría experimentar la política si se ampliara el Estado para que ingresaran las demandas sociales, creó una radicalización de las fuerzas más reaccionaras en las élites políticas, tanto conservadoras como liberales, que, a juicio del autor, estuvieron preparadas para enfrentar la siguiente propuesta de corte popular.

La normalidad constitutiva del concepto de populismo que plantea Kalmanovitz es la de un movimiento que, en la Argentina como caso espejo con Juan Domingo Perón, surge desde el agotamiento del liberalismo y la fortaleza e independencia de los trabajadores y obreros (Kalmanovitz, 1985, p. 359). En Colombia, por el contrario, la excepcionalidad se consolida desde la idea de que es justamente el liberalismo el que puede dar cabida a un proceso populista. Por eso es en él, en el histórico y tradicional Partido Liberal, donde se afinca la propuesta de Jorge Eliécer Gaitán.

El movimiento gaitanista puede caracterizarse como populista: interpela al pueblo por medio de consignas democráticas y nacionalistas, y se enfrenta a la oligarquía, pero sin pretender una transformación radical de la sociedad y de sus relaciones de propiedad y trabajo [...] El gaitanismo nace además en momentos en que los proyectos políticos de las clases dominantes giraban hacia la derecha y se endurecían frente a la actividad de las clases dominadas. [...] Gaitán desarrolla entonces una lucha por las aspiraciones popular-democráticas, en forma antagónica con respecto a la ideología y el poder dominantes. (Kalmanovitz, 1985, pp. 392-393)

La conceptualización del populismo colombiano de Kalmanovitz en 1985 se aleja de lo propuesto por Palacios (1971), pero su construcción de las particularidades del fenómeno político recurre igualmente a la idea contrafactual de lo que hubiese significado un gobierno de Gaitán. De nuevo, la invención de la excepcionalidad colombiana desde la imaginación de un pasado ilusorio. Para Palacios, posiblemente con el liberal en el poder, el país sería más justo con los trabajadores y más progresista. La idea de la Colombia que no fue se arraiga una vez más con fuerza en los análisis que las ciencias sociales ofrecen y hacen de sus conclusiones callejones sin salida, incomprobables.

Dos años después de Economía y nación, se imprimió en español el libro Orden y violencia: Colombia, 1930-1953 del sociólogo francés Daniel Pécaut, quien para 
entonces era conocido en Colombia por sus publicaciones en la década de 1970 sobre grupos sindicales en el país, trabajos que le habían otorgado el particular e informal título de "colombianólogo".

En Orden y violencia, con un recorte temporal de 1930 a 1953, el populismo colombiano por antonomasia es el gaitanismo. El autor insiste en hacer un recorrido diacrónico para buscar antecedentes políticos, sociales y económicos que permitieron su emergencia como un fenómeno de masas inscrito en un ambiente de violencia establecida por las élites y el bipartidismo. Para Pécaut, el populismo no es un "simple fenómeno ideológico", sin contenido, pues constituye una serie de relaciones sociales y se desarrolla en condiciones históricas que facilitan su surgimiento. Los populismos superan la expresión de los antagonismos sociales en "un doble sentido": no son fenómenos conducidos por una clase específica, ni se fundan exclusivamente en una relación social instituida; por el contrario, representan "un exterior a lo social que trastorna la simbólica política preexistente", que incluye una referencia al Estado "como si este, en la figura de un líder carismático, representara la unidad de la sociedad no sometida a la ley" (Pécaut, 2012, p. 378).

Las clases populares, carentes de una identidad política, fueron el soporte de la llegada del populismo gaitanista para inicios de la década de 1940. Las clases obreras colombianas, disociadas y sin identidad, se sintieron atraídas por una oferta política que entiende las dificultades sufridas por la modernización y promete otorgarles un sentido de pertenencia político:

Disociaciones / identidad política, conflictos de clase / redistribución, dominación estatal / nuevo pacto social: el populismo se inscribe en estas tensiones y las transcribe en una representación de lo político fundada sobre parejas de oposiciones entre las cuales, a pesar de las reconciliaciones imaginarias, no hay síntesis posible. El populismo extrae su fuerza de su aptitud para encontrar un fundamento en lo contradictorio, como si fuera insensible a ello; pero encuentra su límite en la imposibilidad de sustraerse a lo imposible que lleva dentro de sí mismo. (Pécaut, 2012, p. 381)

7 Varios extranjeros dedicaron su carrera al estudio de Colombia. Entre los nombres más reconocidos están David Bushnell, Frank Safford, Charles Bergquist y Daniel Pécaut. Los historiadores Peralta y LaRosa entrevistaron a 31 académicos extranjeros que tenían a Colombia como su objeto de estudio y publicaron el libro Los colombianistas: Una completa visión de los investigadores extranjeros que estudian a Colombia (Peralta y LaRosa, 2015). Muchos de los académicos reconocen, además, que ser extranjero resultó ser un beneficio en un país que parece sentirse más cómodo (y seguro) narrando su historia a los foráneos. 
El gaitanismo presenta varias de esas oposiciones y Pécaut destaca tres. Primero, la afirmación de una relación social instituida y un exterior de lo social que no hace parte de la institución. Segundo, la continua referencia al "igualitarismo" y a la "jerarquía". Este igualitarismo, sin embargo, no es un mero equiparamiento entre pueblo y oligarquía, sino la promesa de una unidad popular y de la restauración de los derechos y las oportunidades perdidas y arrancadas por la oligarquía, aun cuando no se precisa si esas oportunidades llegaron si quiera a existir. El tercer binomio es situar en la palestra la división radical entre la sociedad y la "vocación del Estado" por unificarla. Ante las contradicciones de esas tres oposiciones aparece como "último recurso" la figura de Gaitán que, como líder carismático, habla en nombre de la nación y se transforma en el medio para que el pueblo se exprese y logre sus objetivos.

Según Pécaut (2012), el precio que se pagó por el intento de la inclusión de las masas en el sistema político colombiano fue la profundización de la hegemonía bipartidista y de la influencia de las élites económicas en el manejo de las políticas estatales, así como el fortalecimiento de la violencia. "El gaitanismo, igualmente, pretendiendo dar forma política a la informe materia social, llevó finalmente al paroxismo la disyunción entre lo social y lo político. En este sentido, la violencia se sitúa una vez más en la prolongación del populismo" (p. 555). La articulación dependiente entre conceptos políticos polisémicos adquiere en Pécaut un carácter explícito: el populismo en Colombia no puede ser definido sin entender la violencia que es, además, uno de los fundamentos democráticos de esa nación. La democracia colombiana se sostiene en las adhesiones de identidades colectivas partidistas, su defensa incluso violenta, y la creciente dominación social por las élites.

En Pécaut, el populismo colombiano es anómalo no porque desencadene en violencia o porque venga de ella. Su aporte al debate pasa por entender que la violencia, como eje diacrónico de la historia nacional, tiene una capacidad invasiva en cualquier comportamiento y atraviesa, sincrónicamente, los distintos fenómenos políticos que vive el país en el siglo XX, incluido, por supuesto, el gaitanismo. Violencia y populismo se unen de forma diferente. No es el populismo como proceso inacabado que no logra el poder o sus características de débil sustento en el nacionalismo o el sindicalismo lo que genera la anomalía colombiana. La invención de la excepcionalidad colombiana en Pécaut es la violencia como un agente concreto tanto del Estado como de las élites que da forma a lo político.

Con Pécaut, se cierra la primera década y media del debate por la definición del concepto de populismo en las ciencias sociales colombianas. Una época que permite dar luz sobre la manera en la cual los esfuerzos por su definición se cons- 
tituyen en referencias de época mientras paralelamente transforma los lenguajes que son usados por los intelectuales para dar forma a sus análisis sobre los procesos sociales y políticos. Tanto en su aparición en tanto fenómeno como en su estudio conceptual, el populismo es, en últimas, el síntoma de una crisis política profunda.

En Colombia, la discusión en torno al concepto de populismo llega tarde, cuando en otras latitudes el análisis tenía un camino importante. Tanto los estudios de la década de 1970 como los de la década de 1980 generan la articulación dependiente entre populismo y violencia. Ese lazo indisoluble forma el núcleo de la invención de la excepcionalidad colombiana que se construye, en parte, por las consecuencias internas que el populismo trajo. Para los intelectuales estudiados Colombia es anómala porque la violencia se impone a cualquier forma de insti-tución política.

\section{El cierre de un siglo convulso y la llegada de un populismo "de resaca"}

En la década de 1990 y la primera década del siglo XXI, los debates por la conceptualización de un fenómeno considerado escaso o inexistente en el país, y que hacía parte de su excepcionalidad, se mantuvieron vivos gracias a los mismos intelectuales que los iniciaron en las décadas de 1970 y 1980, principalmente Pécaut y Palacios, y al ingreso de nuevos académicos que se sumaron a su estudio: el historiador César Augusto Ayala en la década de 1990 con sus trabajos sobre la Anapo, y los politólogos Cristina de la Torre y Luis Guillermo Patińo en el siglo XXI, enfocados en Álvaro Uribe. Todos, desde diferentes esquinas y desde hipótesis muy diversas, concluyen en la misma articulación dependiente: en Colombia, es imposible definir el concepto de populismo si no se habla del concepto de violencia.

Como hemos visto, Koselleck (1993) habla de un estrecho vínculo entre la historia de los conceptos y la historia social, y explica la forma en que una sociedad tiene una relación en tensión con sus conceptos "en común". En este punto, resulta evidente para el caso colombiano cómo la violencia se transformó con el paso de las décadas, desde mediados del siglo XX, en un concepto no solo común, sino rector de los lenguajes usados por los intelectuales colombianos que pone los límites y, al mismo tiempo, desvía otros conceptos políticos polisémicos como el populismo. 
$\mathrm{Al}$ cierre del siglo XX, los intelectuales escriben desde los suelos de articulación de una sociedad aterrorizada por el aumento de la violencia, y luego, en la primera década del XXI, desde la Presidencia de derecha de Álvaro Uribe, y una guerra frontal entre el Gobierno y la las Fuerzas Armadas Revolucionarias de Colombia (FARC). Ese ambiente impregna los estudios y las conceptualizaciones de un aire de urgencia que plantea la necesidad de buscar alternativas para detener el desangre del país. Es allí donde se presenta lo que hemos denominado el tercer y cuarto pico interpretativo, impulsados también por reacomodos políticos en América Latina: primero, en la década de 1990, con las presidencias neoliberales que llevan a acuñar la variante neopopulismo y, posteriormente, en la primera década del siglo XXI con el arribo de gobiernos autodefinidos como progresistas y, particularmente, con el caso de Hugo Chávez en Venezuela que se convertiría en el nuevo caso espejo en el que Colombia verá reflejada su excepcionalidad.

En Colombia, la llegada del tercer pico interpretativo sobre el populismo, impulsado por una irrupción del neoliberalismo en la Presidencia de César Gaviria, se superpone al segundo pico y coincide, en las ciencias sociales, con una búsqueda de las raíces de las guerrillas y de la incursión en la política de los integrantes del M-19 que abandonaron las armas. Sobre ese pico se van a plegar nuevos análisis que se detienen en el proceso de Rojas Pinilla como populista. Si bien existe una idea mayoritaria de que la dictadura de Rojas Pinilla no fue una expresión acabada del populismo, y lo populista sería en cambio su proceso con la Anapo, en las nuevas interpretaciones de finales del siglo XX se empiezan a perfilar ideas que le endilgan al periodo 1953-1957 "actitudes populistas". El concepto empieza a transformarse mientras cambian al mismo tiempo los lenguajes usados por los intelectuales en los que es posible hallar el populismo no solo como fenómeno, sino como "actitudes" que pueden ser vinculadas a movimientos no "completamente populistas". Lo que antes era un concepto concreto ahora es amplio e inabarcable.

Un exponente de esa nueva mirada es el historiador César Ayala Diago que le dedicará dos décadas al estudio de la dictadura de Rojas Pinilla (1953-1957), a los orígenes de la Anapo, su evolución y su desaparición tras las elecciones de 1970. Tras los esfuerzos de Palacios, Kalmanovitz ${ }^{8}$ y Pécaut, Ayala es el cuarto intelectual en el debate del populismo colombiano, en el cierre de un siglo y el comienzo

8 En el cierre del siglo XX y en la primera década del siglo XXI, Kalmanovitz no profundizó sobre el populismo. En 1998, publicó Neoliberalismo e intervencionismo: Sus fuentes y sus razones, donde apenas se refiere a los procesos populistas en América Latina como fenómenos intervencionistas perjudiciales para la economía. 
del otro. Si bien sus trabajos no se inscriben en la consolidación conceptual ni abordan una perspectiva teórica del populismo, su análisis de los hechos ocurridos en torno a Rojas Pinilla ofrece uno de los estudios más amplios en las ciencias sociales sobre el anapismo como encarnación del populismo existente, pero que no llegó al poder en Colombia en las décadas de 1960 y 1970.

En el artículo "Los orígenes del anapismo como variante colombiana del populismo, 1959-1965), Ayala (1990) se aventura a ofrecer una hipótesis contraria a los postulados de Palacios y de Pécaut sobre el fenómeno, al asegurar que el populismo en Colombia puede rastrearse no como un proceso trunco sino como uno real (existente), cuya particularidad radica en que su evolución no se da desde la doctrina liberal de las colectividades históricas, sino desde las corrientes "pragmáticamente conservadoras de ambos partidos tradicionales" (p. 29). El populismo colombiano para Ayala es conservador, puede etiquetarse como una variable de los otros populismos latinoamericanos y es tangible, principalmente, en la experiencia de la Anapo y de su líder el general Rojas Pinilla.

En 1995, Ayala publicó Nacionalismo y populismo: Anapo y el discurso político de la oposición en Colombia, 1960-1966. Luego, en 1996, Resistencia y oposición al establecimiento del Frente Nacional: Los origenes de la Alianza Nacional Popular, Anapo. Colombia, 1953-1964. En Nacionalismo y populismo, Ayala aclara desde las primeras líneas que su objetivo no es teorizar sobre el populismo, sino reconstruir la forma en que Rojas Pinilla, desde su partido político, organiza una variante colombiana del fenómeno, primero, como alternativa conservadora y, posteriormente, como espacio de concentración de las más diversas propuestas políticas que tenían en común la inconformidad con el Frente Nacional. El populismo anapista se sustenta, según el autor, en la posibilidad de unir las terceras fuerzas, tanto liberales como conservadoras, opuestas al régimen hegemónico. La articulación dependiente entre populismo y violencia toma en Ayala una dimensión diferente, al igual que su aporte para inventar la excepcionalidad nacional. No es, como en ciertos intelectuales pioneros, que el populismo no llegue al poder y lleve a enfrentamientos armados, sino que la posibilidad de la violencia se mantiene presente en el movimiento populista, como una latencia amenazante desde la cual se protege su futuro.

En Resistencia y oposición al establecimiento del Frente Nacional, Ayala explora los años de la dictadura de Rojas Pinilla, el fin de su Gobierno y los orígenes de la Anapo. El populismo de Rojas Pinilla, según el historiador, toma fuerza al entender que en él y en su propuesta se encarna una alternativa viable al poder que podría aprovecharse de las múltiples fracciones en las que habían caído los 
grandes partidos. La enorme fuerza que gana en su discurso el tema popular y el concepto de pueblo son suficientes en Ayala para definir que Rojas Pinilla y su partido son populistas. Casi una década después, cuando Ayala cierra su trilogía sobre la Anapo en 2006, la ampliación de su concepto de populismo se sostendrá sobre la base de un suelo de articulación definido no solo por el neoliberalismo, sino por una nueva oleada de presidencias progresistas que fueron relacionadas con los fenómenos nacional-populares de la primera mitad del siglo XX. La transformada realidad geopolítica tendría un efecto notorio en sus trabajos y en la forma de aproximarse al concepto, incluso con la aparición del caso espejo de Chávez y su proceso bolivariano.

Desde una orilla distinta, Pécaut, el intelectual que había hecho carrera con su hipótesis de la transversalidad de la violencia en la historia colombiana, volvió al ruedo del debate por la definición del populismo y procuró, según los nuevos acontecimientos, poner al día el concepto. En 2000, publicó el artículo "Populismo imposible y violencia: El caso colombiano". Las características de lo que es entendido como neopopulismo, con economías liberales y liderazgos carismáticos, obligan a que Pécaut delimite nuevamente las coordenadas de su definición conceptual. Así, lo que antes fue un fenómeno político específico, tiene ahora tres vertientes: una centrada en la construcción de Estado nacional, una segunda que insiste más en las contradicciones sociales como lo pretendieron Gaitán y su caso espejo Perón, ${ }^{9}$ y una tercera, más frágil, que considera las desigualdades sociales y llama la atención sobre ellas, pero no sacude las estructuras sociales. Es lo que el autor define como "populismo filantrópico" o un "simple estilo populista". Todas las vertientes buscan la creación de un nuevo orden y en ellas el líder es fundamental. "Las configuraciones populistas constituyen una manera de evocar otra ficción, conforme con esta realidad, la de un pacto fundador por el que el pueblo toma forma política gracias a un líder y sin pasar por los mecanismos clásicos de representación" (Pécaut, 2000, p. 51). El rasgo del liderazgo ha tomado un papel protagónico.

9 En su artículo de 2000, Pécaut retoma el caso espejo de Perón para interpretar a Gaitán y sostiene que, si bien tienen aspectos similares, los diferencia la profundidad de sus programas. Sobre ambos líderes señala: "Aunque el sistema de oposición en torno al cual se construye el discurso gaitanista presenta una cierta homología con el peronismo, comprobamos que las diferencias son considerables, ya que para Gaitán el pueblo no es un sujeto político" (p. 55). Insiste también, como lo había hecho en Orden y violencia, que el gaitanismo, a diferencia del peronismo, tiene una muy mala relación con los sindicatos y que Gaitán, a diferencia del argentino, no pudo romper tan fácilmente su vínculo con los partidos porque las subculturas partidistas subsisten. Así fue como la viabilidad del proyecto populista de Gaitán se vio comprometida. Pécaut concluye que para 1947, un año antes del magnicidio, el populismo gaitanista se difuminó en "beneficio del de la violencia" (p. 57). 
En este trabajo, Pécaut también realiza un pliegue interpretativo sobre Rojas Pinilla y la Anapo. Coincide en el debate con aquellos como Palacios o Ayala que no ven en la dictadura de Rojas Pinilla (1953-1957) un populismo consolidado e insiste en que es el periodo anapista de la década de 1960 el que configura el fenómeno. El populismo de la Anapo, conservador, es diferente del de Gaitán, aunque no por ello menos importante. Para 1970, el desgaste del bipartidismo era evidente y las consecuencias de las elecciones de abril de ese año se sentirían por décadas, con el recuerdo de una oferta de populismo "filantrópico", más tímido que el de Gaitán y más moderado. El populismo de la Anapo no pone en tela de juicio los valores tradicionales, no propone ir contra las instituciones, no ofrece una reforma agraria y, una vez derrotado, no impulsa una batalla contra el bipartidismo. El vínculo entre populismo y violencia en el caso de la Anapo es menos evidente que en el 9 de abril de 1948 y toma forma desde el relato de cómo, históricamente, las oligarquías colombianas detienen, con muerte o corrupción, a los movimientos populares. El robo de las elecciones en las que triunfó Rojas Pinilla, según sus seguidores, es el símbolo de la hegemonía intransigente y es contra ese símbolo que los jóvenes se van a armar, incluso cuando muchos de ellos no estaban de acuerdo con la ideología anapista.

En momentos en los cuales se cierra la agitada década de 1990 y el neoliberalismo parece direccionar el debate conceptual hacia el neopopulismo, y ante las evidentes dificultades para instaurar un fenómeno populista en Colombia, Pécaut se pregunta si ahora, con un tamiz de liberalismo económico y casi opuesto a los populismos clásicos, el fenómeno tendría cabida en el país. La respuesta es no. En Colombia, el populismo no solo es incompleto o fallido, es, simplemente, imposible.

$\mathrm{Al}$ igual que Pécaut, Palacios regresa al debate en el siglo XXI con una mirada nueva sobre los espejos en los cuales Colombia debería mirar su experiencia populista y ahora la referencia es Venezuela. El punto de partida lo da su artículo de 2000 "Presencia y ausencia de populismo: Un contrapunto colombo-venezolano".

En este, Palacios regresa a sus miradas contrafácticas al asegurar que el populismo "condujo" a Colombia a la violencia política, mientras en Venezuela, por el contrario, facilitó la democracia a finales de la década de 1950 gracias a reformas sociales que le ahorraron la lucha armada y la posterior consolidación de grupos insurgentes que, si bien existieron, fueron débiles. El contrapunto entre Colombia y Venezuela es un claro resultado de un suelo de articulación cambiante y políticamente convulso: la llegada a Miraflores de Hugo Chávez. Palacios ve al presidente venezolano como un populista, pero advierte que puede representar el último de la vieja estirpe de populistas antiguos latinoamericanos. Aun cuando 
para ese momento el intelectual considera a Chávez como un político moderado, con un amplio apoyo popular, que no pretende grandes transformaciones económicas, lo sitúa lejos de los neopopulistas de aperturas económicas cercanos al consenso de Washington de la década de 1990. Al parafrasear al nobel colombiano Gabriel García Márquez y a su novela Cien años de soledad, se pregunta si el venezolano podría ser catalogado de "un populista con cola de cerdo" como reflejo de su comportamiento extemporáneo, más cercano a la idea del fin de una era que al principio de otra:

En el versátil espectro populista, ¿̇ónde podremos ubicar a Chávez y al chavismo? Las ramas latinoamericanas de la familia extensa de los populistas se asemejan a los Buendía de Macondo, tal como aparece en el manuscrito de Melquíades. Al igual que en este, los populistas parecen condenados a vivir una historia circular de promesas y desilusiones. Su proclividad a la endogamia, y aun al incesto, embrolla las líneas del linaje de modo que la cola de cerdo con que llega al mundo el último Aureliano paga los apetitos y desvaríos de todos sus antepasados. [...] Sin embargo Chávez no parece ganarse la extremidad por ser el último de la estirpe, sino por su obstinada intención de volver a los orígenes míticos y abultar más un legajo truculento de ilusión y fracaso. (Palacios, 2000, pp. 75-76)

Lo que esbozó Palacios en sus estudios de 2000 y 2001 sobre Venezuela fue el inicio de una nueva ola de interpretaciones en torno al concepto de populismo y el neopopulismo en las ciencias sociales colombianas como respuesta a la elección consistente, a lo largo de toda la primera década del siglo XXI, de gobiernos latinoamericanos de izquierda considerados populistas. La elección en 1998 de Hugo Chávez en Venezuela, de Evo Morales en 2006 en Bolivia y de Rafael Correa en 2007 en Ecuador consolidó el cuarto pico interpretativo en los debates y obligó, una vez más, a plegarse sobre acontecimientos estudiados, para buscar, en su resignificación, nuevas aristas que pudieran dar luces sobre la particularidad nacional. Pero, además, mientras América Latina giraba políticamente hacia la izquierda, Colombia escogió como presidente en 2002 a Álvaro Uribe, un mandatario de derecha que, paradójicamente, era también catalogado de populista. El camino gubernamental de derecha colombiano, en contravía del que tomaba el resto del continente, afianzó la idea del país como caso excepcional en la región.

Cristina de la Torre publicó en 2005 el primer libro en la academia colombiana que se centró en la figura de Uribe como un neopopulista vinculado extemporáneamente a los presidentes latinoamericanos neoliberales de mediados de las décadas de 1980 y 1990 conocidos por su inclinación plebiscitaria y apoyo de los medios de comunicación masivos, así como por su relación con los ciudadanos 
sin intermediación de instituciones. Uribe es, según la académica, un neopopulista que desindustrializa y concentra el ingreso en unos pocos. En su liderazgo y en su propuesta programática, el presidente expone una tentación autoritaria que se canaliza en su discurso con insistencia por reformar la justicia. Uribe será, "tras los amagos de Gaitán y Rojas Pinilla, el primer verdadero populista de Colombia en cien años. Aunque populista del nuevo tipo, lo que significa el renacimiento del caudillo en clave neoliberal" (p. 16).

En 2007, se publicó otro libro que miró con cierto detalle la figura de Álvaro Uribe como un neopopulista. Con el segundo mandato uribista en proceso (2006-2010), Luis Guillermo Patiño publicó Del populismo al neopopulismo en América Latina, en el que entiende el fenómeno como un proceso cíclico que une a procesos políticos diversos e, incluso, opuestos y, posteriormente, se concentra en la idea del neopopulismo como "una nueva-vieja forma de representación política en el continente que creció en los últimos años gracias a la deslegitimación de las instituciones políticas tradicionales (Patiño, 2007, p. 7).

La figura del líder pasa a ser central en la resignificación que Patiño hace de los populismos. Un liderazgo que depende de la fuerte cultura mística latinoamericana y del "catolicismo popular tradicional" (Patiño, 2007, p. 45), lo que genera un vínculo religioso. Al acercarse a Colombia, Patińo coincide con Palacios en la articulación de populismo y violencia, y recuerda cómo los países que no tuvieron populismos en Centroamérica fueron fecundos en guerrillas: "el populismo, con todas sus fallas y contradicciones, inhibió parte de la violencia en los países donde se materializó" (p. 51).

Tanto los trabajos de De la Torre como el de Patińo evidencian una nueva era en el debate por la definición conceptual del populismo en Colombia en relación con los acontecimientos que pretendían explicar, siempre articulados a la presencia de la violencia nacional. Para el fin del siglo XX, el concepto de populismo sufrió una escisión, impulsada fundamentalmente por la necesidad de explicar procesos políticos neoliberales con características distantes de aquellas que se les endilgaron en los populismos clásicos. Se habla de "actitudes" o "características populistas", vinculadas principalmente con un líder carismático, la demagogia y, en algunos casos, la irresponsabilidad fiscal. Pioneros en el debate conceptual como Palacios o Pécaut, que antes usaron el concepto para explicar fenómenos políticos limitados, empezaron a hablar de populismo económico o populismo político. La articulación del populismo con la violencia no solo se mantenía sino que se hacía más fuerte, algo no menor si consideramos que los nuevos contextos de debate los ubicaban, en el caso de Palacios o Kalmanovitz, como rectores de 
universidades públicas, gerentes de bancos nacionales o, incluso, como asesores gubernamentales para implementar políticas públicas de educación.

El neoliberalismo primero y la llegada de presidencias progresistas en América Latina después llevaron a nuevos intentos por definir el populismo, a repensar y resignificar el proceso de Rojas Pinilla y de la Anapo con más detenimiento, y considerar que, con la llegada de Álvaro Uribe en 2002, Colombia seguía su particular camino anómalo en contravía de un continente que giraba hacia la izquierda. Con un discurso de derecha, su principal promesa era acabar con las guerrillas, cuyo vínculo parecía doble con el populismo. Por un lado, eran organizaciones que se enfrentaban a la misma hegemonía que frenó los fenómenos populares del siglo XX, por otro lado, y quizá con mayor impacto en el relato uribista, movimientos como las FARC tenían vínculos con la Presidencia de Chávez a quien el término populista se le aplicaba con frecuencia. De esta forma, se confi-gura el segundo caso espejo de este debate, en el que Colombia se va a reflejar para entender sus propios procesos populistas y definirse como anómala: un espejo más cercano y asimilable que aquel que brindó Perón y Argentina. Un espejo en el que, además, se ven las dificultades de la simbólica nacional colombiana, al reflejarse con el bolivarismo chavista.

Lo paradójico es que, como reconoce Palacios (2000), cuanto más presente se hacía el concepto de populismo, menos necesario era para analizar procesos que se nombraban como prototípicos del fenómeno. Los estudios coinciden en que el populismo en Colombia existió con Gaitán y con la Anapo (en ambos casos detenido en su ascenso al poder) y de forma anacrónica en Uribe; sin embargo, de los tres podría hacerse un detallado estudio sin recurrir al concepto. Siempre respecto de los intelectuales y el periodo estudiado, encontramos en el populismo un concepto que adquiere con el tiempo mayor carga semántica, menor concreción y es más fácilmente prescindible. A esto hay que sumarle, además, las dificultades de algunos académicos que pretendían categorizar a personajes como Chávez y Uribe como populistas a pesar de estar en las antípodas, cuyo vínculo era, casi exclusivamente, su "carisma" y la difícil relación de cada uno con las instituciones democráticas.

La primera década del siglo XXI pone sobre la mesa un debate sobre el concepto de populismo cada vez más cerca del análisis de coyuntura que del análisis teórico. Así es como los intelectuales, de a poco, cambian el tono en los libros y en los artículos científicos, y el debate amplía su espacio de circulación a columnas de opinión y periodísticas en los principales diarios nacionales. Esta incursión en el periodismo impulsó en sus lenguajes políticos un cambio irreversible en el uso del concepto de populismo hacia un adjetivo calificativo peyorativo. Al retomar la 
mirada de Skinner sobre la doble cara de los conceptos politicos, podemos afirmar que en estos nuevos contextos de debate el uso de la palabra populismo, o populis$t a$, pasó a ser, casi exclusivamente, evaluativo en detrimento de su cara descriptiva.

Al mismo tiempo, la primera década del siglo XXI fue para Colombia, bajo la Presidencia uribista y según estos intelectuales, una etapa de identificación nacional y de exacerbado patriotismo que desde el discurso presidencial se sustentaba en la necesidad de unidad para enfrentar a un enemigo nacional encarnado en las FARC, y a uno internacional, ilustrado en el Gobierno de Chávez. Así, el venezolano, además de ser populista, y caso espejo para reflejar la excepcionalidad colombiana, constituía la paradoja de ser parte indispensable de la construcción del nacionalismo en el que se sustentaba el populismo uribista. Y nos enfrentamos a una nueva paradoja constitutiva en la definición conceptual. Más que una simple contradicción, la paradoja es la imposibilidad de definir al populismo uribista sin el nacionalismo que impulsa, sustentado este a su vez en el populismo chavista al que se opone. Las ramificaciones para los lenguajes políticos que utilizan los intelectuales que participan en los debates serán amplias. Desde la necesidad de explicar una y otra vez sus posturas hasta las simples y llanas contradicciones.

\section{Los espacios periodísticos como esferas de ampliación conceptual}

En medio del agitado inicio de siglo, con el incremento de la violencia, Pécaut, Palacios, Kalmanovitz y De la Torre, expusieron en periódicos y revistas sus puntos de vista sobre la situación que aquejaba al país. En ellos, el concepto de populismo, atravesado y afectado por la coyuntura, se expandió rápidamente, de los espacios limitados del círculo académico, a tribunas diarias que ofrecieron otro uso del concepto tan frecuente como impreciso. Sus análisis periodísticos se circunscriben, en una inmensa mayoría, a artículos de opinión publicados en los diarios nacionales El Espectador, El Tiempo y Semana, aunque aparecen también en esta época análisis esporádicos, escritos por Palacios, en los periódicos El País de España y la revista web Razón Pública.

Aun cuando los lenguajes expositivos de los intelectuales se transforman al ofrecer su mirada sobre el concepto desde espacios de coyuntura, la especificidad de la mirada de cada cual se mantiene. Así es como en el caso de Palacios su énfasis para usar el concepto en sus columnas de opinión va de la mano de una retrospectiva histórica, su imposibilidad y su mirada como proceso inconcluso 
desencadenador de violencia. Sin embargo, su definición de populismo dejó de circunscribirse al fenómeno político específico para ser adjetivo calificativo igual a la demagogia. En 2008, en un artículo para Razón Pública, al hablar de las FARC y del vínculo "ideológico" de estas con Simón Bolívar, describe al libertador como "caraqueño, aristócrata y populista".

En Pécaut, el análisis de sus opiniones está articulado con un propósito notorio de explicar la evolución del conflicto armado. Y para los dos intelectuales que se presentaron como columnistas de El Espectador desde 2007, Salomón Kalmanovtiz y Cristina de la Torre, sus miradas del populismo van a estar ligadas a las relaciones entre Uribe y Chávez, sus diferencias y sus semejanzas. Los títulos de las columnas de De la Torre dan cuenta del enfoque. El 4 de diciembre de 2007, publica "Duelo de populismos"; el 10 de mayo, "El legado de Fujimori", en el que compara al peruano con el colombiano al que denomina "la resaca solitaria del neoliberalismo", y el 27 de enero de 2009, "Uribe-Chávez: ¿gemelos enemigos?”. En el caso de Kalmanovitz, además, sus columnas nos ofrecen una arista económica del fenómeno que, como ya hemos visto en el cierre del siglo XX, fue fundamental para la asimilación del concepto con el neologismo contradictorio de neopopulismo. El concepto de populismo, en este punto del debate, ha perdido la esperanza de concreción.

La invención de la excepcionalidad colombiana en relación con sus procesos políticos y el vínculo entre el populismo y la violencia encuentra en la primera década del siglo XXI una época particularmente prolífica y efervescente que lleva el ejercicio conceptual, finalmente, a difuminarse en el análisis de ocasión. Los intelectuales que desde 1970 intentaron explicar parte de la anomalía colombiana por la falta de un populismo clásico, cuya ausencia fue propulsora de la Violencia primero y las diferentes violencias después, tuvieron dificultades para explicar el fenómeno de Álvaro Uribe como un presidente neoliberal y de derecha que controvertía los cánones de su tiempo. En ese sentido, lo excepcional ahora de Colombia no era su ausencia de populismo, sino la presencia de uno que no compartía los distintivos del momento político progresista latinoamericano. Un populismo anacrónico y "en resaca”.

Al mismo tiempo, la presencia avasallante de Chávez en Venezuela, a quien también definían como populista, llevó al debate a desconocer sus propios límites para tratar de explicar dos fenómenos en los opuestos del arco político que eran descritos bajo un mismo concepto. Si Álvaro Uribe, un político de derecha, cercano discursivamente a los Estados Unidos y con propuestas económicas neoliberales, era populista y, al mismo tiempo populista era Chávez, desde la izquierda, 
abiertamente antimperialista y crítico con las posturas de la economía del mercado, ¿qué era entonces el populismo? La referencia de movimientos o ideologías específicas se transformó en la categorización de diversas actitudes.

\section{Conclusiones}

$\mathrm{Al}$ recorrer los debates por la definición de populismo desde sus primeros estudios en 1970 hasta el fin de la primera década del siglo XXI, pasando por la aparición de la definición de neopopulismo, desenterramos no solo la evolución de un concepto por momentos ańorado y por momentos defenestrado, sino la insistencia de cómo son las violencias, pasadas y presentes, las que estructuran la dinámica propia del acontecer colombiano e inventan la excepcionalidad de un país que se considera diferente y anómalo respecto de sus vecinos latinoamericanos. Mientras seguíamos las huellas del concepto, pudimos ver su evolución de la mano de la situación política que lo sustenta, primero como el fenómeno del pueblo enfrentado a los poderes hegemónicos que, detenido a balazos en 1948, impulsó la Violencia y las violencias siguientes, y por último como el estilo de un Gobierno de derecha propulsado por una guerra contra la guerrilla y sostenido en el miedo que vendía.

El concepto del populismo en Colombia es un termómetro particular de su historia democrática contemporánea. Con sus desgracias y con sus crisis. Con sus violencias y con sus intentos desesperados por pacificarse. ¿Somos entonces realmente tan diferentes? ¿Respecto de quiénes nos diferenciamos? La obsesión de los intelectuales que participan en el debate por enfrentarnos a casos espejo, sea el caso de Perón en Argentina o de Chávez en Venezuela, resultan no pocas veces en la construcción de ideales tipo que obvian debilidades o amplifican logros. Que mezclan dimensiones de análisis o coyunturas históricas diversas.

En las ciencias sociales colombianas, lo que atraviesa la conceptualización del populismo es la violencia como centro del proceso nacional. ${ }^{10}$ Sin un fenómeno

10 Valga la pena señalar que en los últimos años (fuera de nuestro periodo estudiado) han aparecido nuevos y valiosos trabajos dedicados a repensar el populismo colombiano desde otras miradas y bajo novedosas ópticas que entienden al fenómeno ya no como experiencias políticas concretas, sino desde la perspectiva política de procesos identitarios. Remitimos al lector al reciente libro Descentrando el populismo: Peronismo en Argentina, gaitanismo en Colombia y lo perdurable de sus identidades políticas, coordinado por Ana Lucía Magrini (2021) y escrito por un grupo de investigadores colombianos y argentinos que se dedican a pensar lo perdurable de las identidades políticas en el gaitanismo y el peronismo. 
que haya permitido la consolidación de una idea de nación, la violencia pasó a ser el proceso en torno al cual se aglutina la realidad del país. Somos en tanto violentos. Siempre en torno a los intelectuales estudiados, lo propio y excepcional, recae en el populismo como antecedente de la violencia en los casos del gaitanismo, del rojismo en el poder (en menor medida) y del anapismo; y como resultado de esta en el uribismo, un movimiento cuyo sustento es ir a la guerra contra la subversión con la promesa de que, después de mil desgracias, enfrentamos por fin la batalla final.

En ese sentido, uno de los hallazgos de la investigación es la fuerza de las posturas contrafácticas y el análisis de la historia presente en las ciencias sociales colombianas como una especie de teleología a la inversa, cuyos acontecimientos pasados son aprendidos, relatados y resignificados con la lupa de las consecuencias vividas. En las conceptualizaciones del populismo estudiadas, resulta apabullante la insistencia en las posibilidades nunca recorridas y las hipótesis sobre futuros irrefutables, que, según algunos intelectuales, serían mejores pero que nunca existieron. Es en la superficie de las múltiples violencias que los intelectuales van a debatir sobre el concepto de populismo y los populismos posibles. Y sobre los acontecimientos que disparan los significados y las conceptualizaciones, la violencia imposibilita el fenómeno gaitanista de la década de 1940 que lo habría cambiado todo (y para siempre), o se acelera tras la denuncia de robo a la Anapo en las elecciones de 1970. Al despuntar el siglo XXI, es esa misma violencia la que va a impulsar a Álvaro Uribe y su populismo en resaca, de nueva índole, pero paradójicamente trasnochado para la nueva centuria, que va en contravía de los fenómenos clásicos y que interviene para que, desde los lenguajes políticos de los intelectuales, el concepto sea casi exclusivamente una categoría comportamental.

El largo recorrido por la evolución de los debates aparece también como un problema dividido en dos etapas. En la primera, en el siglo XX, los esfuerzos conceptuales se enfocaron en redefinir desde el presente violento los hechos traumáticos de 1948 y 1970, y con frecuencia forzaron sus rasgos para explicar sus resultados. En el segundo momento, entrado el siglo XXI, el hecho, el análisis y la conceptualización transcurrieron paralelamente, y los debates dieron paso al uso intuitivo del concepto para delimitar una coyuntura cuya aceleración imposibilitó la mesura analítica. Ambas etapas (y problemas) nos parecen que representan, en últimas, los enormes retos del análisis histórico-conceptual e, incluso, nuestra propia relación con el tiempo y su papel en la construcción del relato de la excepcionalidad nacional. Son problemas del compás de la historia que en Colombia acelera o disminuye en relación con sus conflictos. 


\section{Referencias}

Altamirano, C. (2005). Para un programa de historia intelectual y otros ensayos. Siglo XXI.

Ayala Diago, C. A. (1990). Los orígenes del anapismo como variante colombiana del populismo, 1959-1965. Controversia, 162-163, 29-53. https://doi.org/10.54118/ controver.v0i162-63.1127

Ayala Diago, C. A. (1995) Nacionalismo y populismo: Anapo y el discurso político de la oposición en Colombia. 1960-1966. Universidad Nacional de Colombia.

Ayala Diago, C. A. (1996). Resistencia y oposición al establecimiento del FN. Universidad Nacional de Colombia.

Ayala Diago, C. A. (2001). La perversión del populismo en Colombia o el ocaso del Movimiento Revolucionario Liberal (MRL). Palimsestus, 1, 182-199. https://revistas. unal.edu.co/index.php/palimpsestvs/article/view/82504

Ayala Diago, C. A. (2006). El populismo atrapado, la memoria y el miedo: El caso de las elecciones de 1970. La Carreta.

Betancur, B. (1970). Populismo vs. establecimiento. En Á. Gómez Hurtado (ed.), Populismo. Editorial Revista Colombiana.

De la Torre, C. (2005). Álvaro Uribe o el neopopulismo en Colombia. La Carreta.

De la Torre, Cristina. (2007, 4 de diciembre). Duelo de populismos. El Espectador.

De la Torre, Cristina. (2008, 19 de julio). El trío dinámico. El Espectador. https://www. elespectador.com/opinion/columnistas/cristina-de-la-torre/el-trio-dinamico-column-27018/

De la Torre, Cristina. (2009, 27 de enero). Uribe-Chávez: ¿Gemelos enemigos? El Espectador. https://www.elespectador.com/opinion/columnistas/cristina-de-la-torre/ uribe-chavez-gemelos-enemigos-column-111975/

Di Tella, G. (1973). Populismo y reformismo. En O. Ianni, G. Germani y T. S. Di Tella, Populismo y contradicciones de clase en Latinoamérica (pp. 38-82). Era.

El Tiempo. (2004, 8 de febrero). Diagnóstico europeo sobre Colombia. https://www. eltiempo.com/archivo/documento/MAM-1509707

Escobar, A. (1998). La invención del Tercer Mundo: Construcción y deconstrucción del desarrollo. Norma.

Fals Borda, O (1989). Movimientos sociales y poder político. Análisis Político, 8, 49-59. https://revistas.unal.edu.co/index.php/anpol/article/view/74240

Germani, G. (1971). Política y sociedad en una época de transición. Paidós.

Gómez Hurtado, A. (1970). Conservatismo y el populismo. En A. Gómez Hurtado (ed.), Populismo. Editorial Revista Colombiana.

Kalmanovitz, S. (1985). Economía y nación. Norma.

Kalmanovitz, S. (1998). Neoliberalismo e intervencionismo: Sus fuentes y razones. Revista de Estudios Sociales, 1, 33-38. https://journals.openedition.org/revestudsoc/31302

Kalmanovitz, S. (2007, 7 de noviembre). Chávez y Uribe. El Espectador. https://www. elespectador.com/opinion/columnistas/salomon-kalmanovitz/chavez-y-uribe-column-572/

Kalmanovitz, S. (2010). Nueva historia económica de Colombia. Taurus. 
Koselleck, R. (1993). Futuro pasado: Para una semántica de los tiempos históricos. Paidós. Koselleck, R. (2010). historia/Historia. Trotta.

Leal Buitrago, F. (1988). La profesionalización de los estudios políticos en Colombia. Análisis Político, 3, 49-62. https://revistas.unal.edu.co/index.php/anpol/article/ view/73978

López Michelsen, A. (1970). El liberalismo y el populismo. En A. Gómez Hurtado (ed.), Populismo. Editorial Revista Colombiana.

Magrini, A. L. (2018). Apuntes metódicos para una historia y política como significación. En R. Farrán y E. Biset (coords.), Métodos: Aproximaciones a un campo problemático (pp. 253-286). Prometeo.

Magrini, A. L. (coord.) (2021). Descentrando el populismo: Peronismo en Argentina, gaitanismo en Colombia y lo perdurable de sus identidades políticas. Universidad del Rosario.

Neiburg, F. (1988). Los intelectuales y la invención del peronismo. Alianza.

Palacio Rudas, A. (1970). Populismo: Esencia y apariencia. En A. Gómez Hurtado (ed.), Populismo. Editorial Revista Colombiana.

Palacios, M. (1971). El populismo en Colombia. Siuasinza.

Palacios, M. (1995). Entre la legitimidad y la violencia: Colombia entre 1875 y 1994. Norma.

Palacios, M. (2000). Presencia y ausencia de populismo: Un contrapunto colombo-venezolano. Análisis Político, 39, 57-78. https://revistas.unal.edu.co/index.php/anpol/ article/view/79675

Palacios, M. (2002, 6 de agosto). Un presidente 'de a caballo'. El País. https://elpais.com/ diario/2002/08/07/internacional/1028671207_850215.html

Palti, E. J. (2014). ¿Las ideas fuera de lugar? Estudios y debates en torno a la historia político-intelectual latinoamericana. Prometeo.

Palti, E. J. (2018). Una arqueología de lo político: Regímenes de poder desde el siglo XVII. Fondo de Cultura Económica.

Patiño Aristizábal, L. G. (2007). Del populismo al neopopulismo en América Latina. Universidad Pontificia Bolivariana.

Pécaut, D. (2000, 2 de julio). Hilos de la madeja. El Tiempo. https://www.eltiempo.com/ archivo/documento/MAM-1226467

Pécaut, D. (2000). Populismo imposible y violencia: El caso colombiano. Estudios Políticos, 16, 45-70. https://revistas.udea.edu.co/index.php/estudiospoliticos/article/ view/16703

Pécaut, D. (2012). Orden y violencia: Colombia, 1930-1953. Siglo XXI.

Peralta, V. y LaRosa, M. (2015). Los colombianistas: Una completa visión de los investigadores extranjeros que estudian a Colombia. Academia Colombiana de Historia.

Santos Gómez, D. (2020). El populismo en Colombia y la obra de Marco Palacios: Una reflexión desde los lenguajes políticos. Papel Político, 25. https://doi.org/10.11144/ Javeriana.papo25.pcom

Skinner, Q. (2007). Lenguaje, política e historia. Universidad de Quilmes. 